J. Amer. Soc. Hort. ScI. 116(3):569-573. 1991.

\title{
Combining Ability for Canopy Growth and Gas Exchange of Interspecific Blueberries under Moderate Water Deficit
}

\author{
W.A. Erb' and A.D. Draper ${ }^{2}$ \\ Fruit Laboratory, Agricultural Research Service, U.S. Department of Agriculture, Beltsville, \\ MD 20705 \\ H.J. Swartz ${ }^{3}$ \\ Department of Horticulture, University of Maryland, College Park, MD 20742 \\ Additional index words. Vaccinium ashei, V. myrtilloides, V. myrsinites, V. corymbosum, V. darrowi, V. atrococcum, \\ $V$. angustifolium, fruit breeding, drought resistance
}

Abstract. Progenies and clones of interspecific hybrid blueberries were evaluated for annual fraction of canopy volume (FCYV) and for difference in fraction of canopy volume between control and stressed plants [FCYV(C) $\operatorname{FCYV}(S)]$ in a moderate water-deficit environment. The FCYV $(C)$ - FCYV (S) data were used to determine combining ability effects. In addition, physiological processes of attached leaves of the clones were monitored with a portable photosynthesis apparatus. Specific combining ability (SCA) effects were significant for FCYV(C) - FCYV(S). The clone with the lowest mean for FCYV(C) - FCYV(S) was US75, a hybrid of Vaccinium darrowi Camp x V. corymbosum L. Clone JU64 (V. myrsinites Lamark x V. angustifolium Aiton) also had a low FCYV(C) - FCYV(S) mean, and its two progenies (JU64 x JU11 and G362 x JU64) had low progeny means. Stomatal conductance was lowered when blueberries were exposed to atmospheric and/or soil moisture stress that resulted in lower transpiration and photosynthesis and increased or equal water-use efficiencies (WUE). Blueberry plants adjusted to moisture stress as the season progressed by lowering stomatal conductance and increasing WUE. In particular, stressed plants of US75 and JU64 had equal or higher WUE values than control plants. US226 was the most drought-susceptible clone in the study, and its stomata did not appear to be as responsive to moisture stress as the other clones. Breeding for higher WUE in a dry environment appears possible with the germplasm used in this study.

Increased drought resistance is an important trait for future highbush blueberry cultivars. In much of the United States, water is a limited resource and must be rationed in years of extreme drought. A more drought-resistant blueberry would be adapted to new areas for production and would allow growers to produce a crop in dry years when irrigation is halted or limited. Genetic variability for drought resistance is present in Vaccinium spp. Some southern species grow in nutrient-impoverished sands subjected to frequent drought (Davies and Albrigo, 1984; Galletta, 1975; Lyrene and Sherman, 1980). In previous studies (Erb et al., 1988a, 1988b), a drought screening test was developed. Accessions of some southern species (V. darrowi Camp, $V$, elliotti Chapman, and $V$. ashei Reade) were more droughtresistant than northern accessions ( $V$. corymbosum, $V$. vacillans Torrey, and $V$. myrtilloides Michaux) (Erb et al., 1988b). In addition, clones deriving half their genes from a southern species were usually drought-resistant (Erb et al., 1988b). Davies and Albrigo (1984) suggested the above-mentioned southern species plus $V$. tenellum Aiton, $V$. myrsinites, and $V$. simulatum Small, and the northern species $V$. angustifolium and $V$. pallidum Aiton as good sources of drought resistance.

The water relations of $V$. ashei cultivars were first investigated in the late 1970s. Andersen et al. (1979) observed that irrigation reduced leaf diffusive resistance by $50 \%$ and increased transpiration by $70 \%$ over nonirrigated bushes of 'Tifblue',

Received for publication 6 Nov. 1989. The cost of publishing this paper was defrayed in part by the payment of page charges. Under postal regulations, this paper therefore must be hereby marked advertisement solely to indicate this fact.

'Graduate Student. Presently: Assistant Professor, Dept. of Horticulture, Ohio Agricultural Research and Development Center, Wooster, OH 44691.

${ }^{2}$ Research Geneticist.

${ }^{3}$ Associate Professor.
'Woodard', and 'Bluegem', but found no significant effect on midday stem xylem pressure potentials for either treatment. In addition, seasonal changes in nonirrigated bushes of $V$. aslei for leaf diffusive resistance and transpiration suggested adaptation to drought conditions. Davies and Johnson (1982) concluded that rabbiteye blueberries are intermediate in drought tolerance compared to field beans, sorghum, and apples because they have a relatively low critical water potential for stomatal closure, low transpiration ratios, and low changes in relative water content per unit change in water potential. Aside from observations on the habitat of various Vaccinium species (Davies and Albrigo, 1984; Galletta, 1975; Lyrene and Sherman, 1980), little is known about the physiological response to drought in most Vaccinium spp.

This study was initiated to estimate drought stress effects on interspecific blueberry clones and progenies and to determine combining abilities for the difference in fraction of canopy volume between control and moderately drought-stressed plants.

\section{Materials and Methods}

Design of experiments. The study was conducted in 1985 with five 5-year-old clones (JU11, JU64, US75, US226, and G362) (Table 1) and eight progenies growing in a Galestown fine sandy loam, reddish-brown adult soil $(0.7 \%$ to $0.1 \%$ organic matter) at Beltsville, Md. Six progenies were from one set of $\mathrm{F}_{1} \mathrm{~s}$ of a four-parent diallel (JU11, US75, US226, and G362), and the other two progenies were crosses of JU64 (G362 × JU64 and JU64 × JU11).

Abbreviations: A, net photosynthesis; CYV, canopy volume; E, transpiration; FCYV, fraction of canopy volume; GCA, general combining ability; g', leaf conductance of water; LT, leaf temperature; SCA, specific combining ability; VPD, vapor pressure deficit; WUE, water-use efficiency. 
The field was originally laid out in 1982 (Chandler et al., $1985)$ in a randomized complete block design with 10 replications of each progeny (10 seedlings per replication); each replication had a plot containing two plants of each parent. Data were taken on the clonal material and four randomly chosen seedlings from each plot. The field was fertilized with $\left(\mathrm{kg} \cdot \mathrm{ha}^{-1}\right.$, $28 \mathrm{~N}, 12.3 \mathrm{P}$, and $23.2 \mathrm{~K}$ in mid-May and $23 \mathrm{~N}$ as $\left(\mathrm{NH}_{4}\right)_{2} \mathrm{SO}_{4}$ in early July.

The field was divided into a control and drought-stressed side. Plants on both sides were drip-irrigated using an 8-mil (2 mm) twin-wall-lateral with prepunched holes every $30 \mathrm{~cm}$. Soil tension was monitored with tensiometers placed $15 \mathrm{~cm}$ from the twin-wall lateral. The control side consisted of four blocks that were irrigated when the soil tension reached 0.03 to $0.40 \mathrm{MPa}$ at a depth of $15 \mathrm{~cm}$, and the stressed side was the remaining six blocks that were irrigated when soil tension reached 0.08 to $0.09 \mathrm{MPa}$ at a depth of $25 \mathrm{~cm}$. After the proper tension level was reached, plants were irrigated for 8 to $12 \mathrm{~h}$ to bring soil tension to field capacity.

Plant growth The annual FCYV was estimated by measuring the canopy volume $(\mathrm{CYV})$ (height $\times$ width $\times$ breadth) of the plants in October of each year by: (1985 CYV - 1984 CYV)/ 1985 CYV. The FCYV for each stressed seedling or clone was then subtracted from the mean FCYV of their control plants to give the difference in FCYV between the control and stressed plants $[\mathrm{FCYV}(\mathrm{C})-\mathrm{FCYV}(\mathrm{S})]$. The lower the value, the more drought-resistant the entry. Data were subjected to diallel analysis using the Schaffer and Usanis (1969). computer program, and $\mathrm{F}$ ratios and general combining ability (GCA) and SCA effects were calculated according to Griffing's method 4 and model I analysis (Griffing, 1956).

Physiological characteristics. A LI-COR 6000 portable photosynthesis apparatus (LI-COR, Lincoln, Neb.) was used to simultaneously monitor apparent net photosynthesis (A), transpiration $(\mathrm{E})$, leaf conductance of water $\left(\mathrm{g}_{1}\right)$, leaf temperature (LT), irradiance, and chamber $\mathrm{CO}_{2}$ concentration, temperature, and relative humidity. Two fully expanded leaves in the upper southern half of the canopy of each of five clones were analyzed. A 0.25 -liter leaf chamber with a return flow rate of 7.0 to $7.4 \mathrm{~cm}^{3} \cdot \mathrm{s}^{-1}$ circulating within a closed system was used. Six 7-sec observations were made on each leaf, and the mean of the observations was used for analysis. WUE was calculated as $\mathrm{A} / \mathrm{E}$. Measurements were made on attached leaves horizontal to the soil surface on sampling dates corresponding to soil tension levels of 0.08 to $0.09 \mathrm{MPa}$ at a depth of $25 \mathrm{~cm}$. The physiological data were analyzed as a split-split-split plot design. The main plots were control and stressed and the subplots were clones (two plants per clone per field were sampled), which were further split into four dates during the growing season (9

Table 1. Ploidy level $(X=12)$ and species included in the parentage of the five parental Vaccinium clones.

\begin{tabular}{lcc}
\hline Clone & Ploidy & Constitution \\
\hline JU11 & $6 \mathrm{X}$ & $\begin{array}{c}\text { Tifblue (Vaccinium ashei Reade) } \times \text { US41 } \\
\text { (V. atrococcum Heller) (Colchiploid) }\end{array}$ \\
JU64 & $4 \mathrm{X}$ & $\begin{array}{c}\text { V. myrsinites Lamark } \times \text { V. angustifolium } \\
\text { Aiton }\end{array}$ \\
US75 & $4 \mathrm{X}$ & $\begin{array}{c}\text { Fla-4B }(V . \text { darrowi Camp) } \times \text { Bluecrop }(V . \\
\text { corymbosum L.) }\end{array}$ \\
US226 & $4 \mathrm{X}$ & $\begin{array}{l}\text { V. myrtilloides Michaux } \times \text { V. atrococcum } \\
\text { (Colchiploid) }\end{array}$ \\
G362 & $4 \mathrm{X}$ & V. corymbosum
\end{tabular}

and 21 June, 22 July, and 14 Aug.) and two periods of the day (morning, between 0900 and $1100 \mathrm{HR}$, and afternoon, between 1330 and $1530 \mathrm{HR})$.

\section{Results and Discussion}

Plant growth. The differences in FCYV between the control and stressed plants provide an estimate of drought stress. There were no significant differences in FCYV between stressed clones, but US75 had the lowest FCYV(C) - FCYV(S) and US226 the highest (Table 2). In the seedling populations, JU64 $\times$ JU11 had the lowest FCYV(C) - FCYV(S) and was significantly different from JU11 $\times$ US226 and G362 × US75 (Table 3). Some inbreeding depression probably occurred in the progeny of JU11 $\times$ US226 because the same V. atrococcum Heller clone is present in the background of each parent. G362 × US75 is threequarters $V$. corymbosum, a species found predominantly in swampy areas (Galletta, 1975). Hybrid vigor for FCYV(C) FCYV(S) maybe present in JU64 $\times$ JU11, G362 $\times$ JU64, JU11 $\times$ US75, US75 × US226, US226 × G362, and G362 × JU11 because the mean of their progeny is lower than either clonal mean.

Our measure of drought resistance did have a bias against JU11 and US75, if one considers fruit load per plant and canopy space filling. JU11 was the only clone that had a significantly larger total fruit yield (Erb et al., 1990) and was vigorous enough to have filled its allowed canopy space. US75 was also vigorous enough to fill its allowed canopy space, indicating the reduced vigor exhibited by JU11 is probably due to the fruit load difference. In a previous study (Erb et al., 1988b), JUll was the dominant clone followed closely by JU64 and then G362 and US75 and finally US226.

Diallel analysis indicated GCA to be nonsignificant and SCA

Table 2. Mean annual fraction of canopy volume (FCYV) of blueberry clones subjected to a water deficit $[\mathrm{FCYV}(\mathrm{S})]$ and subtracted from control values [FCYV(C)].

\begin{tabular}{lcc}
\hline \hline Clone & FCYV(S) & FCYV(C) - FCYV(S) \\
\hline US75 & 0.63 & $0.05 \mathrm{a}$ \\
JU64 & 0.61 & $0.10 \mathrm{ab}$ \\
G362 & 0.57 & $0.17 \mathrm{ab}$ \\
JU11 & 0.58 & $0.18 \mathrm{ab}$ \\
US226 & 0.54 & $0.25 \mathrm{~b}$ \\
\hline
\end{tabular}

${ }^{2}$ Means not significantly different; each value is the mean of six observations (except two for US226).

'Mean separation within columns by Duncan's multiple range test, $P$ $=0.05$.

Table 3. Mean annual FCYV of blueberry interspecific hybrid progeny subjected to a water deficit $[\mathrm{FCYV}(\mathrm{S})]$ and subtracted from control values [FCYV $(\mathrm{C})]$.

\begin{tabular}{lcc}
\hline \hline Cross & FCYV $(S)^{z}$ & FCYV(C) - FCYV(S)y \\
\hline JU64 x JU11 & 0.64 & $-0.10 \mathrm{ay}$ \\
G362 x JU64 & 0.41 & $-0.01 \mathrm{ab}$ \\
JU11 x US75 & 0.62 & $0.01 \mathrm{ab}$ \\
US75 x US226 & 0.61 & $0.01 \mathrm{ab}$ \\
US226 x G362 & 0.53 & $0.05 \mathrm{ab}$ \\
G362 x JU11 & 0.54 & $0.05 \mathrm{ab}$ \\
G362 x US75 & 0.54 & $0.09 \mathrm{~b}$ \\
JU11 x US226 & 0.44 & $0.26 \mathrm{c}$ \\
\hline
\end{tabular}

${ }^{z}$ Means not significantly different; each value is the mean of $18 \mathrm{ob}-$ servations.

'Mean separation within columns by Duncan's multiple range test, $P$ $=0.05$. 
to be highly significant for FCYV(C) - FCYV(S). The lowest estimates for SCA effects were for JU11 $\times$ US75 $(-0.05)$ and the highest were for JU11 $\times$ US226 (0.09). The genetic variability for growth in this moderate water-deficit environment can be exploited through recurrent selection and recombination only if large populations are examined. The four interspecific hybrids used in this diallel represent only a fraction of the total variability present in Vacciniun and none of them are composed of two drought-resistant species. Crosses between northern and southern blueberry species produce drought-resistant progeny (Erb et al., 1988b). The populations of JU64 crossed with US75 and US226 were not included in this study, so JU64 could not be used in the diallel analysis. However, the responses of the two JU64 populations suggest that it might be a good general combiner for FCYV(C) - FCYV(S).

Physiological characteristics. The water deficit affected physiological processes and confirmed previous observations on rabbiteye blueberries (Table 4) (Andersen et al., 1979; Davies and Johnson, 1982) in which a moderate water deficit decreased leaf conductance. The significantly lower $\mathrm{g}_{1}$ for the stressed plants indicates stomata closed in response to the moderate water stress, resulting in one of the reasons for the reduced $\mathrm{E}$ and $\mathrm{A}$. The amount of reduction in A caused by stomatal closure and direct damage to the photosynthetic process was not determined. The reduced $\mathrm{E}$ and $\mathrm{A}$ resulted in a lower WE for the stressed plants.

Comparison of physiological characteristics for different times of the day (Table 4) indicated that E increased in the afternoon and A decreased. However, there was no significant change in $\mathrm{g}_{1}$. The significantly higher LT in the afternoon probably caused $\mathrm{E}$ to rise. The higher afternoon LT is the effect of a higher mean afternoon irradiance and a higher mean afternoon air temperature. The mean difference in vapor pressure deficit (VPD) between the morning $(2.07 \mathrm{kPa})$ and the afternoon $(3.26 \mathrm{kPa})$ was either not large enough to produce a significant difference in stomatal closure and/or osmotic adjustment was occurring to keep stomata open. Leaf conductance was significantly lower in 'Bluecrop' ( $V$. corymbosun) and Fla-4B (V. darrowi) when VPD was raised from 1 to $3 \mathrm{kPa}$ and temperature was raised from 20 to 30C (Moon et al., 1987a).

Clonal differences are presented and discussed by date. On 9 June, there was no difference between JU11 (2) plants in either the morning or the afternoon for $\mathrm{A}, \mathrm{E}, \mathrm{g}_{1}$, or WUE (Fig. 1). However, A was higher for the control plants of both G362 (1) and US226 (3) in the morning and afternoon, and E was higher in the afternoon for the stressed plants of US226, while it was lower for the stressed plants of G362. Leaf conductance was reduced in the G362 stressed plants, but there was no difference between the US226 plants. WUE was lower for only G362 stressed plants in the afternoon, but for US226 it was lower in both the morning and afternoon. JU11 and G362 responded to water stress by closure of stomata, which conserved moisture and maintained WUE. This result indicates that G362 (V. corymbosum) and JUll (V. ashei $\times \mathrm{V}$. atrococcum) possess mechanisms to resist moderate water-deficit environments. In plant growth, G362 was as drought-resistant as JU11, but in a severe moisture-stress environment (Erb et al., 1988b), JU11 was more drought-resistant. Thus, G362 and JU11 may possess similar mechanisms for resisting a moderate water deficit, but G362 lacks the mechanisms needed to resist severe water stress. The stressed plants of US226 had a higher E in the morning and the afternoon and a much lower $\mathrm{A}$, which resulted in a lower WE. US226 had the same $g_{1}$ in both environments. Evidently, its stomates remained open. The stomata of US226 did not appear to be as responsive to moisture stress as the other clones.

On 21 June, the control plant means for A were higher than the stressed plant means for G362 and JU11- in the morning and for $\mathrm{E}$ in both the morning and the afternoon (Fig. 2). Leaf conductance was higher in the morning and afternoon for G362 control plants and higher for the control plants of JU11 and US226 only in the afternoon. The stressed plants of US226 in the morning were higher in $\mathrm{g}_{1}$ than the stressed plants of G362 and JU11. There were no differences in WUE between plants in the morning or afternoon. The lower $g_{1}$ in the stressed plants was the reason for the equal WUE in the control plants. The stomata of US226 responded more on 21 June than on 9 June. However, the reduced stomatal response in US226 may have been one of the reasons for its poor performance in a moderate drought stress. It had the highest FCYV(C) - FCYV(S) compared to the other clones (Table 1).

On 22 July (Fig. 3) and 14 Aug. (Fig. 4), US226 had to be dropped from the study due to a lack of sample leaves left on the plants. However, measurements were obtained on JU64 (4) and US75 (5) in addition to G362 and JU11. JU11 and G362 followed a similar pattern on 22 July and 14 Aug. as on 9 and 21 June. Leaf conductance was lower for the stressed plants, but WUE was similar for the control plants. However, the control plants were higher in $\mathrm{A}$ and $\mathrm{E}$.

The response of G362 and JU11 suggests that blueberries can adjust to high temperature and drought stress during the growing season. The mean WUE values for G362 and JU1l control plants were 1.04 and 0.62 on 9 June (Fig. 1) (air temperature 29.4C) and 1.03 and 0.92 on 14 Aug. (Fig. 4) (air temperature 39.6C), respectively; in the afternoon, WUE values of stressed plants of G362 and JU11 were 0.53 and 0.46 on 9 June and 0.74 and 0.71 on 14 Aug., respectively. Stomata adjustment occurs in apples (Lakso, 1979), peaches (Xiloyannis et al., 1980), and rabbiteye blueberries (Andersen et al., 1979). Stomata were less sensitive to water stress near the end of the season.

US75 was not affected as greatly by moderate water stress as

Table 4. Instantaneous gas exchange moisture and time means for blueberry clones monitored on four dates in 1985 for $\mathrm{E}, \mathrm{LT}, \mathrm{g}_{\mathrm{i}}, \mathrm{A}$, and WUE.

\begin{tabular}{lcccccc}
\hline \hline Comparison & No. samples & $\begin{array}{c}\mathrm{E} \\
\left(\mathrm{mmol} \cdot \mathrm{m}^{-2} \cdot \mathrm{s}^{-1}\right)\end{array}$ & $\begin{array}{c}\mathrm{LT} \\
\left({ }^{\circ} \mathrm{C}\right)\end{array}$ & $\begin{array}{c}\mathrm{g}_{1} \\
\left(\mathrm{~mol} \cdot \mathrm{m}^{-2} \cdot \mathrm{s}^{-1}\right)\end{array}$ & $\begin{array}{c}\mathrm{A} \\
\left(\mu \mathrm{mol} \cdot \mathrm{m}^{-2} \cdot \mathrm{s}^{-1}\right)\end{array}$ & $\begin{array}{c}\text { WUE } \\
(\mathrm{A} / \mathrm{E})\end{array}$ \\
\hline $\begin{array}{l}\text { Moisture treatment } \\
\quad \text { Control }\end{array}$ & 127 & $7.45 \mathrm{a}^{2}$ & $33.3 \mathrm{~b}$ & $0.32 \mathrm{a}$ & $9.51 \mathrm{a}$ & $1.33 \mathrm{a}$ \\
$\quad \begin{array}{l}\text { Stressed } \\
\text { Time of day }\end{array}$ & 112 & $5.97 \mathrm{~b}$ & $35.0 \mathrm{a}$ & $0.20 \mathrm{~b}$ & $6.86 \mathrm{~b}$ & $1.20 \mathrm{~b}$ \\
$\quad \begin{array}{l}\text { Morning } \\
\text { Afternoon }\end{array}$ & 120 & $6.50 \mathrm{~b}$ & $32.8 \mathrm{~b}$ & $0.28 \mathrm{a}$ & $9.11 \mathrm{a}$ & $1.44 \mathrm{a}$ \\
\hline
\end{tabular}

${ }^{2}$ Mean separation within columns by $\mathrm{F}$ test, $P=0.05$, 

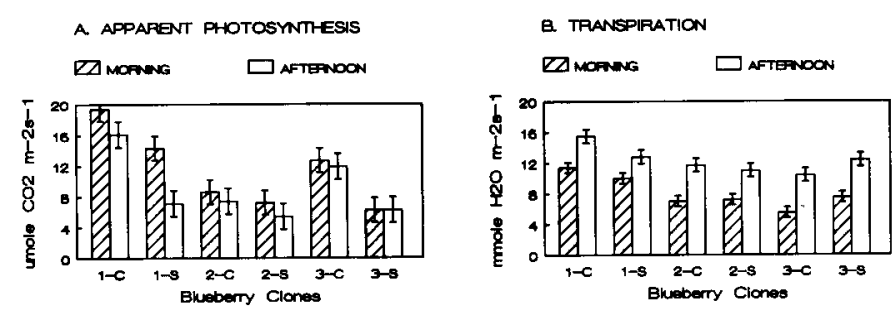

C. LEAF CONOUCTANCE
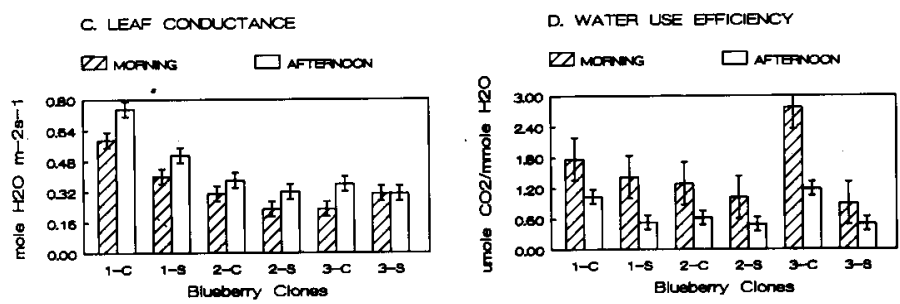

Fig. 1. Instantaneous gas exchange moisture $(\mathrm{C}=$ control and $\mathrm{S}=$ stressed) and time (morning and afternoon) means for blueberry clones $(1=\mathrm{G} 362,2$ = JUll, and $3=\mathrm{US} 226)$ monitored on 6 June 1985 for (A) apparent photosynthesis, (B) transpiration, (C) leaf conductance, and (D) water-use efficiency. Leaf temperatures ranged from 30.4 to $33.6 \mathrm{C}$ in the morning and from 33.4 to $38.2 \mathrm{C}$ in the afternoon. Bars represent SE.
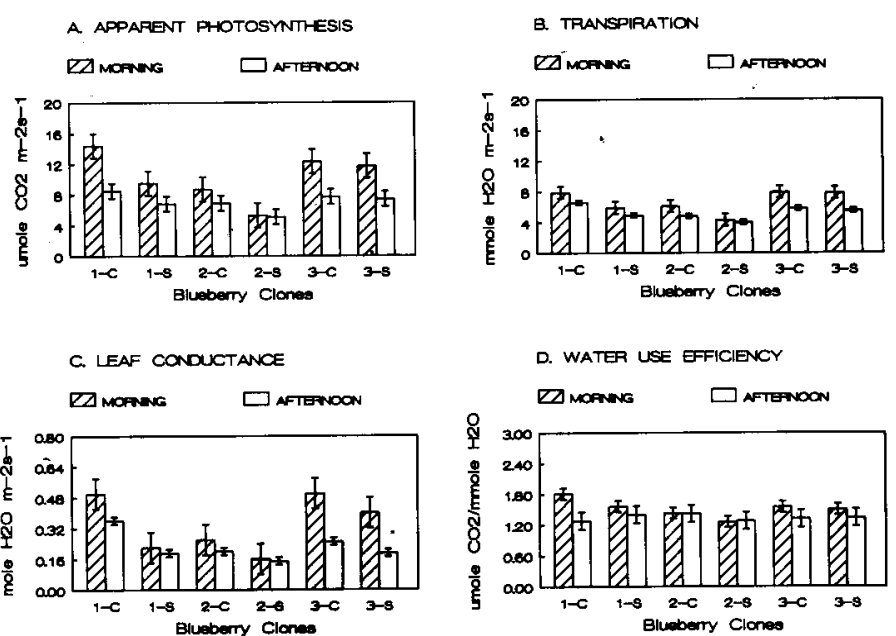

Fig. 2. Instantaneous gas exchange moisture $(\mathrm{C}=$ control and $\mathrm{S}=$ stressed) and time (morning and afternoon) means for blueberry clones $(1=\mathrm{G} 362,2$ = JU1l, and $3=\mathrm{US} 226)$ monitored on 21 June 1985 for (A) apparent photosynthesis, (B) transpiration, (C) leaf conductance, and (D) water-use efficiency. Leaf temperatures ranged from 28.4 to $31.9 \mathrm{C}$ in the morning and from 28.0 to $31.0 \mathrm{C}$ in the afternoon. Bars represent SE.

US226, and both the JU64 progenies were efficient at producing new growth under stress. In the afternoon on 22 July (Fig. 3), WUE for stressed plants of US75 and JU64 was higher than for their comparative control plants, apparently as a result of a lack of difference in A between stress and control plants, but a drop in E. The stressed plants of JU64 also had a lower $\mathrm{g}_{1}$. On 14 Aug. (Fig. 4), the control plants of US75 were higher than the stressed plants in both the morning and afternoon for all the characteristics except WE. The control plants of JU64 were only higher for $\mathrm{g}_{1}$ in the morning. There were no significant differences among the clones or plants for WUE on 14 Aug., but US75 stressed in the afternoon was 0.31 higher than US75 control, and JU64 stressed was 0.07 higher in the afternoon. WUE is thought to increase at lower leaf conductance (Jones,
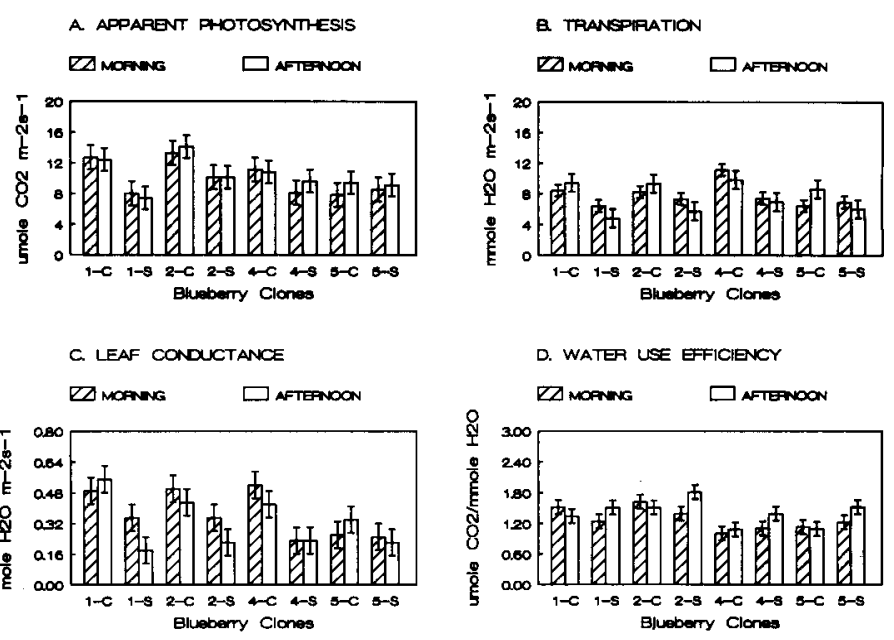

Fig. 3. Instantaneous gas exchange moisture $(\mathrm{C}=$ control and $\mathrm{S}=$ stressed) and time (morning and afternoon) means for blueberry clones $(1=\mathrm{G} 362,2=\mathrm{JU} 11,4=\mathrm{JU} 64$, and $5=\mathrm{US75})$ monitored on 22 July 1985 for (A) apparent photosynthesis, (B) transpiration, (C) leaf conductance, and (D) water-use efficiency. Leaf temperatures ranged from 30.0 to $33.4 \mathrm{C}$ in the morning and from 31.5 to $32.9 \mathrm{C}$ in the afternoon. Bars represent SE.
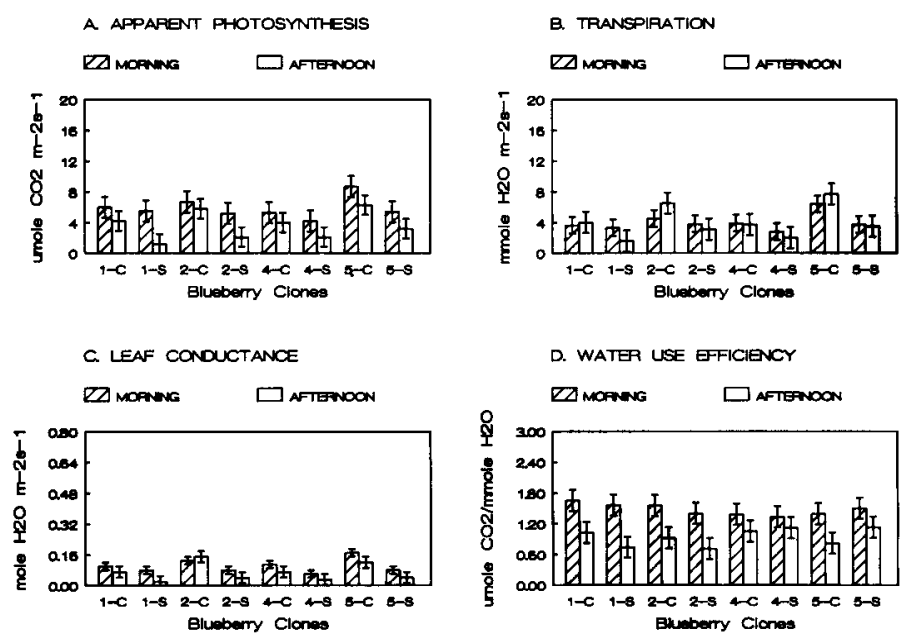

Fig. 4. Instantaneous gas exchange moisture $(\mathrm{C}=$ control and $\mathrm{S}=$ stressed) and time (morning and afternoon) means for blueberry clones $(1=\mathrm{G} 362,2=\mathrm{JU} 11,4=\mathrm{JU} 64$, and $5=\mathrm{US75})$ monitored on 14 Aug. 1985 for (A) apparent photosynthesis, (B) transpiration, (C) leaf conductance, and (D) water-use efficiency. Leaf temperatures ranged from 35.3 to $38.9 \mathrm{C}$ in the morning and from 40.4 to $43.9 \mathrm{C}$ in the afternoon. Bars represent SE.

1983). The higher WUE of drought-stressed US75 and JU64 plants also is characteristic of drought-stressed cassava (El-Sharkaway and Cock, 1984; E1-Sharkaway et al., 1984), apple (Davies and Lakso, 1979; Schneider and Childers, 1941), and orange (Kriedemann, 1971). WUE increased in blueberries when VPD was raised from 1 to $3 \mathrm{kPa}$ in 'Bluecrop', 'Jersey' (V. corymboswn), and Fla-4B (Moon et al., 1987a). The decrease in E can be partly explained by the decrease in leaf conductance. The lower $\mathrm{g}_{1}$ also inhibits A, but to what extent was not determined. The higher WUE characteristic of stressed US75 and JU64 might explain the lower FCYV(C) - FCYV(S) (see Table 1).

On 14 Aug., the highest mean LT (39.6C) occurred, and US75 control plants had a high A in the morning; the control plants of JU11 had a similar rate of A. In laboratory experiments 
with greenhouse-grown plants, US75 and one of its parents (Fla4B) were found to have a $\mathrm{CO}_{2}$ assimilation temperature optimum of 30C (Moon et al., 1987b). The other parent of US75 ('Bluecrop') had a $\mathrm{CO}_{2}$ assimilation temperature optimum of 20C. This high temperature optimum for photosynthesis is a characteristic that probably can be found in other southern Vaccinium spp.; one parent of JU11 is a rabbiteye blueberry ( $V$. ashei). Moon et al. (1987b) concluded that high-temperature $\mathrm{CO}_{2}$ assimilation was a heritable trait in Vaccinium.

These results suggest that blueberry plants lower $\mathrm{g}_{1}$ and, therefore, conserve water when exposed to atmospheric and/or soil moisture stress, resulting in lower $\mathrm{E}$ and $\mathrm{A}$. Blueberries adjusted to these stresses as the season progressed. The effect that reduced E and A had on WUE was clone-, environment-, and phenology-dependent. Lowering stomatal conductance to restrict E and A in US75 and JU64 either increased or maintained WUE. This change appears to be an important mechanism for tolerating water deficits in blueberries. Breeding for higher WUE in a dry environment appears possible with the germplasm used in this study because both US75 and JU64 seem to express this characteristic in different degrees.

In this study, plants were exposed to a moderate water deficit (soil tension levels of 0.08 to $0.09 \mathrm{MPa}$ at a depth of $25 \mathrm{~cm}$ ), and in our drought screening study (Erb et al., 1988b), plants were exposed to severe drought stress (soil tension level of 0.8 $\mathrm{MPa}$ ). Results in this study differed from those of our drought screening study for some clones. US75 was an intermediate clone in the severe drought-stress environment of our earlier study, but it was the most vigorous clone in-this moderate droughtstress environment. US226 was drought-susceptible in both environments, and G362 was intermediate in both environments. JU64 gained interest because it was drought-resistant in both environments and progeny of JU64 crosses were also droughtresistant in both environments. To transfer drought-resistant characters from JU64, blueberry progeny will need to be screened in at least two environments. Drought resistance in one environment cannot be used to predict drought resistance under all circumstances. The ability 'to increase or maintain WUE may be the key mechanism that allowed US75 and JU64 to tolerate a moderate water-stress environment. However, in a more severe water-deficit situation, it appears that other mechanisms might be more important because US75 is not resistant in these situations (Erb et al., 1988b).

\section{Literature Cited}

Andersen, P. C., D.W. Buchanan, and L.G. Albrigo. 1979. Water relations and yields of three rabbiteye blueberry cultivars with and without drip irrigation. J. Amer. Soc. Hort. Sci. 104:731-736.

Chandler, C. K., A.D. Draper, G.J. Galletta, and J.C. Bouwkamp. 1985. Combining ability of blueberry interspecific hybrids for growth on upland soil. HortScience 20:257-258.

Davies, F.S. and L.G. Albrigo. 1984. Water relations of small fruits, p. 89-136. In: T.T. Kozlowski (cd.). Water deficits and plant growth, vol. VII. Academic, New York.
Davies, F.S. and C.R. Johnson. 1982. Water stress, growth, and critical water potentials of rabbiteye blueberry (Vaccinium ashei Reade). J. Amer. Soc. Hort. Sci. 107:6-8.

Davies, F.S. and A.N. Lakso. 1979. Water stress responses of apple trees. L Effects of light and soil preconditioning treatments on tree physiology. J. Amer. Soc. Hort. Sci. 104:392-395.

E1-Sharkaway, M.A. and J.H. Cock. 1984. Water use efficiency of cassava. I. Effects of air humidity and water stress on stomatal conductance and gas exchange. Crop Sci. 24:497-502.

E1-Sharkaway, M. A., J.H. Cock, and A.A. Held K. 1984. Water use efficiency of cassava. H. Differing sensitivity of stomata to air humidity in cassava and other warm-climate species. Crop Sci. 24:503507.

Erb, W. A., A.D. Draper, and H.J. Swartz. 1988a. Methods of screening blueberry seedling populations for drought resistance. HortScience 23(2):312-314.

Erb, W. A., A.D. Draper, and H.J. Swartz. 1988b. Screening interspecific blueberry seedling populations for drought resistance. J. Amer. Soc. Hort. Sci. 113(4):599-604.

Erb, W. A., A.D. Draper, G.J. Galletta, and H.J. Swartz. 1990. Combining ability for plant and fruit traits of interspecific blueberry progenies on mineral soil. J. Amer. Soc. Hort. Sci. 115:1025-1028.

Galletta, G.J. 1975. Blueberries and cranberries, p. 154-196. In: J. Janick and J.N. Moore (eds.). Fruit breeding. Purdue Univ. Press, West Lafayette, Ind.

Griffing, B. 1956. Concept of general and specific combining ability in relation to diallel crossing systems. Austral. J. Biol, Sci. 9:463493.

Jones, H.G. 1983. Plants and microclimate: A quantitative approach to environmental plant physiology. Cambridge University Press, New York.

Kriedemann, P.E. 1971. Photosynthesis and transpiration as a function of gaseous diffusive resistances in orange leaves. Physiol. Plant. 24:218-225.

Lakso, A.N. 1979. Seasonal changes in stomatal response to leaf water potential in apple. J. Amer. Soc. Hort. Sci. 104:58-60.

Lyrene, P.M. and W.B. Sherman. 1980. Horticultural characteristics of native Vaccinium darrowi, V. elliotti, V. fuscatum, and V. myrsinites in Alachua County, Florida. J. Amer. Soc. Hort. Sci. 105:393396.

Moon, J. W., Jr., J.A. Flore, and J.F. Hancock, Jr. 1987a. A comparison of carbon and water vapor gas exchange characteristics between a diploid and highbush blueberry. J. Amer. Soc. Hort. Sci. 112:134-138.

Moon, J. W., Jr., F.W. Hancock, Jr., A.D. Draper, and J.A. Flore. 1987b. Genotypic differences in the effect of temperature on $\mathrm{CO}_{2}$ assimilation and water use efficiency in blueberry. J. Amer. Soc. Hort. Sci. 112:170-173.

Schaffer, H.E. and R.A. Usanis. 1969. General least square analysis of diallel experiment: A computer program diallel. North Carolina State Univ. Genetics Dept. Rpt. 1.

Schneider, G.W. and N.F. Childers. 1941. Influence of soil moisture on photosynthesis, respiration, and transpiration of apples leaves. Plant Physiol. 16:565-583.

Xiloyannis, C., K. Uris, and G.C. Martin, 1980. Seasonal and diurnal variations in abscisic acid, water potential, and diffusive resistance in leaves from irrigated and non-irrigated peach trees. J. Amer. Soc. Hort. Sci. 105:412-416. 